\title{
Coastal Community Resilience to Tsunami: A Study on Planning Capacity and Social Capacity, Dichato, Chile.
}

\author{
Md. Shahinoor Rahman ${ }^{1}$, Teodoro Kausel ${ }^{2}$ \\ ${ }^{I}$ (Lecturer, BUET-Japan Institute of Disaster Prevention and Urban Safety, \\ Bangladesh University of Engineering and Technology, Bangladesh) \\ ${ }_{2}^{2}$ (Professor. Faculty of Economic and Administrative Science, Universidad Austral de Chile, Valdivia, Chile)
}

\begin{abstract}
Coastal communities in Chile are at risk to tsunami like other coastal communities around the world. As resilience is understood as the opposite of vulnerability, it is important to increase community resilience to reduce vulnerability. The Dichato community is one of the most affected communities by the 27 February 2010 earthquake and following tsunami in central Chile and the recovery process is slower there than
\end{abstract} expected.

This paper aims to examine planning capacity and social capacity to evaluate community resilience to tsunami. Qualitative data are collected through interview. Community leaders, high officials (e.g: regional chief of planning ministry, regional urban manager) at local and regional level and also nongovernmental organizations (Hogar de cristo, Red Cross) are interviewed. The collected data is evaluated under a framework which combines eight important resilience elements. These elements are governance, society and economy, resource management, land use and structural design, risk knowledge, warning and evacuation, emergency response and disaster recovery.

Tsunami hazard risks are not well addressed and considered in plans and programs for coastal community like Dichato. Land use and structural design are carefully considered after the tsunami in last year. Pre-established mechanisms for disaster recovery are not appropriate. Community engagement in planning and implementation procedure of these plans and programs are limited. There are very limited training program for livelihood diversification. Training and mock-drill programs for tsunami response are very limited in the community level. Risk knowledge is not shared properly with the community to reduce the risks.

Findings of this paper will open a new horizon that can help to find the strength and weakness of disaster preparedness in community level. Resilience of coastal community to tsunami can be achieved through enhancing planning and social capacity.

Keywords - Community Resilience, Planning Capacity, Social Capacity, Disaster Risk, Vulnerability

\section{INTRODUCTION}

It was February 27, 2010 very early in the morning and 3:34 am local time. Suddenly and unexpectedly, an earthquake of 8.8 magnitudes, the fifth largest instrumentally recorded, struck the central south zone of Chile [1]. Major tsunami waves hit the coast in the following $14 \mathrm{~min}-2 \mathrm{~h} \mathrm{[2]} \mathrm{devastating} \mathrm{coastal} \mathrm{villages}$ and fishing coves along $600 \mathrm{~km}$ of coastline (331360S-381280S). Dichato is a medium sized coastal community is one of the most affected communities by this tsunami where 26 persons died and the community virtually disappeared with 70 percent of homes washed away by the tsunami [3]. Along with that, the tsunami has an adverse impact on livelihood and economy in the long run. Local economy in Dichato which basically depends on fishing and tourism is destroyed severely.

Natural hazard is not a new phenomenon in the human history and societal development. Coastal area is prone to different types of natural hazards. Disaster risk is a function of the hazard and vulnerability of a population to that hazard. Chile is arguably the world's most seismic country and holds the record for the seismic event of greatest energy release [4]. Chile has long coastal area with Pacific Ocean where two-third of the population is living. These people depend directly or indirectly on coastal resources. Therefore coastal communities in Chile are at risk from tsunami hazard.

Since natural disaster is unavoidable and settlement and economic activities have already been placed in risk area. Therefore, it is important to build resilient community to adapt and cope with the disaster like tsunami. An important outcome of increasing the resilience of coastal communities is to reduce or avoid the impact of tsunami by reducing hazard risk and vulnerability. As rehabilitation process in housing and other sectors in Dichato are slower than expectation which brings the question in the ground that is community really resilient to tsunami? Therefore it has now become important to assess the community resilience. This research paper will draw attention to build a resilience community to tsunami pointing on planning capacity in institutional level and social capacity in community level. 


\section{COMMUNITY RESILIENCE}

It is important to understand the meaning of community resilience. Community resilience can be seen in two standpoints. One is relatively more concerned with community resilience as it prevents disaster-related health or mental health problems of community members. The other is relatively more concerned with community resilience as it describes effective organizational behavior and disaster management. These two points sometimes, but not always, informed each other. This paper follows the second statement and accepting two general definition of community resilience. One is given by Paton [5] defines community resilience as the capability to bounce back and to use physical and economic resources effectively to aid recovery following exposure to hazards. Where, Coles [6] refers community resilience as a community's capacities, skills, and knowledge that allow it to participate fully in recovery from disasters. Therefore, community resilience is understood as the capacity of the community to bounce back in original state after disaster (in the case of this paper) with their knowledge, resource, skill and planning as preparation.

Therefore, the activity and living in tsunami vulnerable area increase tsunami risk for coastal community in Chile. A tsunami resilient community is less vulnerable because community can have the capacity to absorb shock. As vulnerability has the inverse relation with resilience, when community lose resilience, it becomes vulnerable to change that previously could be absorbed [7]. This risk can be reduced through enhancing coastal community resilience. Coastal community can be more resilient by enhancing planning capacity and social capacity.

\section{Social CAPACITY}

Lichterman [8] defines social capacity as people's ability to work together to organize public relationships, rather than give responsibility for those relationships wholly to state actors or the flux of market exchange. Spellerberg [9] suggests a definition where social capacity is the aggregate of voluntary relationships between individuals, groups and/or organizations that create an ability to act positively for mutual benefit and a larger common purpose. It features trust, co-operative behavior, inclusiveness and openness, and is driven by a sense of equity and justice.

Here social capacity of the tsunami affected community is the presence of inter-organizational networks that are characterized by reciprocal links, frequent supportive interactions, overlap with other networks, the ability to form new associations, and cooperative decision-making processes. The participatory collaboration mechanism among sectors, social and cultural networks to promote self-reliant community engagement in planning and management are considered as social capacity. In addition with that Community preparedness for the tsunami impact and coordination mechanism for the recovery process is also considered as social capacity in this paper. Therefore, social capacity highlights self-reliance of the community achieved through networks, cultural norms, and education and outreach.

\section{Planning CAPaCity}

Policy and planning now is an important issue in disaster management. Tsunami is a consequence of earthquake in ocean which is followed by different types of disaster. Coastal community is at risk of this consequence of disaster. Therefore, coastal communities need some special policy and planning. Here planning is not merely planning for disaster management. As it is not possible to prevent natural catastrophe it is better to have some plan so that community may face minimum amount of loss and can recover as much as within short period. Planning is needed in disaster preparedness, planning is also needed to protect people from the risk by regulating land use plan and some other measures. Planning is also an important issue in emergency response and disaster recovery. For the community resilience, local and regional government has significant and important roles. It needs to be ensured that planning is being conducted at all levels of government. In this case, planning goal is to developed institutional capacity, strengthening the technical, institutional capacities.

Planning activity focuses on working with decision makers, emergency managers, and humanitarian assistance organizations to first, expand and strengthen institutional technical capabilities; second, to develop and implement information and decision support systems as well as risk and vulnerability assessment tools and procedures; and third, to enhance institutional access to data and information holdings. This plan must set up the structure and mechanisms for dealing with disasters and it must anticipate future disasters.

\section{The STUdY AREA AND MeThODOLOGY}

There are three considerations for the selection of an appropriate community to do the research. First, the study area is experienced a devastating tsunami in recent past. Second, the local economy is mostly dependant on coastal resources. Third, rehabilitation and rebuilding programs are taking place in the study area after the tsunami. Dichato community was selected on the basis of above mentioned criterias. 
The study area of Dichato is a medium-sized coastal town, in region VIII Bio Bio of Chile, the longest country of the world. This town located in the Bay of Coliumo, 10 kilometres north of the communal capital of Tome, and 37 kilometers north of the regional capital of Concepcion. Geographically, the study area is situated between $36^{\circ} 32^{\prime} 56.10^{\prime \prime}$ South and $72^{\circ} 55^{\prime} 58.30^{\prime \prime}$ West, with a land area of 122 hectors. Dichato is surrounded by the small hills of Coliumo Pingueral on three sides of the town, and the west side is open to the Pacific Ocean.

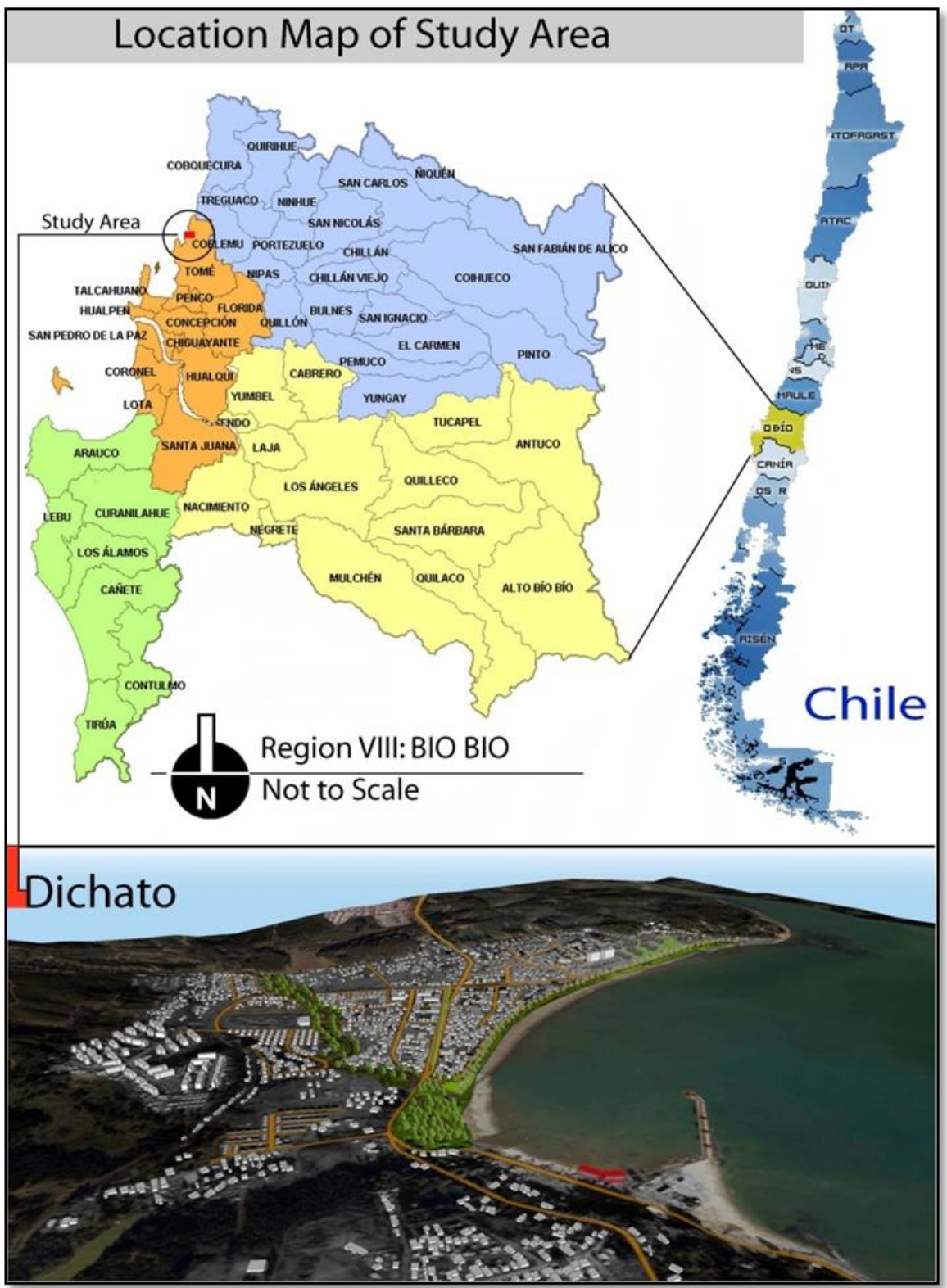

Figure 1: Location Map of the Study Area

Source: Author's own construction based on images from PRBC 18, 2010 and Descubre Bio Bio

Dichato situated on the bank of horse-shaped bay which referred as Coliumo bay and sometimes Dichato bay separately. Dichato has a population of 4046 [10]. However it recorded a population of 3956 people by the census of 2002, of which 3488 correspond to urban population, while 468 would correspond to rural population. Dichato is mostly an urban area containing civic facilities (water, electricity, health and education).

The economic activity of this area is mainly based on fishing and tourism. Because of the sharp growth of the tourism sector in this area, the service sector is also becoming dominant day by day.

To assess the community resilience this paper followed coastal community resilience framework developed by USAID [11] after Indian Ocean tsunami in 2004. This framework set eight elements of resilience as essential for coastal community resilience. These eight elements are government, society and economy, land 
use and structural design, resource management, risk knowledge, warning and evacuation, emergency response and disaster recovery.

The field work is conducted based on qualitative methods through in-depth interview, field observation and reading documents. Two sets of key informants are identified for the interview. One set of key informant are mainly community leaders and other set of key informants are high officials from different government and non-government organizations responsible for community development, disaster management and resource management. The key informants are identified through snow ball method. Therefore, interview is continued to key informant to key informant until there is no variation of information. This process starts with local municipality office. In this process directorate of community development (DIDECO), Secretariat of community planning (SECOLAN), secretariats and sub-secretariats of the ministry of housing and urbanization, the ministry of public works and ministry of internal affairs are identified in local and regional level. Moreover, the national emergency office (ONEMI), fire brigade, local police and NGOs are important key informants. Besides, community leaders such as seven president of neighborhood, president of chambers and commerce, presidents of fishermen association, school teacher, journalists, social worker and president of emergency shelter are identified as key informants.

Two sets of questionnaire prepared for interview, one for community level and another of institutional level. The questions were open ended and the respondents have flexibility to speak in detail on specific issue. During the interview, the interviewee is asked a question with a yes or no option. There were three probabilities to the response, which were 'yes', 'no' or 'do not have idea'. If respondent had no idea then answer was not considered in the scoring. Responses of 'no' gives a score of zero for the specific question but if the answer is 'yes', then the interviewees are asked to give a score on a scale of one to five for the specific question. Here five is 'excellent' and one is 'poor' condition. After selecting a score, the respondents were again asked to justify their score on the issue. Therefore a complete picture can come out of a particular question. This systematical rating system has two advantages. Firstly, the scoring (numerical rating) can be a useful approach to understand the resilience elements easily. Secondly, it gives an opportunity to do cross-comparisons among the elements of resilience. Planning capacity and social capacity can also be compared based on the final score. Average score of each element in each questionnaire is the personal score on element. Therefore, the personal scores for each reliance element are averaged to give an overall indication of resilience for a given capacity (planning or social). Each of the capacity described the condition of coastal community resilience

\section{RESULT DISCUSSION}

\subsection{Governance}

Governance issue in the community resilience is mainly community involvement with the government through leadership, legal framework and participation. For a resilient community, it is essential that community has community development plan, landuse plan, risk management plan where potential hazard risk are considered. Community involvement needs to be ensured in plan preparation as well as implementation process.

In Dichato, Community involvement in the planning process is ambiguous because on the one hand law of transparency gave the citizen right to put their opinion on all planning issues, projects and programs. On the other hand, this process is sometimes an eyewash and not very effective. National emergency office (ONEMI) is planning to take the public opinion through the risk management training in the coastal disaster risk mitigation programs. Community participation is taking place through meetings with community leaders like presidents of neighborhood, president of chambers of commerce and president of fishermen association etc. Representatives of local government explains prospective projects for the community but does not actively involve the community, meaning community is informed about the projects and programs but the arguments and opinions of the local people are not considered properly. Representatives of the municipality, regional government, and community leaders meet periodically to review the various plans and programs. The community representatives and multi-sectoral representatives are jointly organizing some workshops to coordinate the reconstruction process. This practice is enabling the multi-sectoral coordination body for the local development decisions. In addition with that, local people think that in recovery process, local government initiates so many projects very quickly, just after three months of tsunami, necessary studies began to make ground for the recovery. They also took necessary measure to prepare a master plan and coastal protection plan for the community which is considered as good performance of government by local people. However, local people mentioned that the working progress is too slow where after one year construction of only one road and few houses are started among so many projects.

Another important factor is Leadership practice in the community which is well organized. Community people chose their leader in a democratic manner and change in leadership is progressive and regular change by the direct vote after the termination of the period. This coastal community cannot sustain in far away from coastal resource as isolated community. This community culture and livelihood are considered carefully in tsunami mitigation plan. Therefore, mitigation plan propose coastal protection wall and tsunami resistant 
housing to reduce tsunami impact rather than relocation of the people from the original location. It can be concluded here that smooth leadership, multi sectoral coordination and community participation are the very positive sign to enhance community resilience to tsunami. Community engagement is also needed to consider in tsunami hazard risk assessment and indentify measures to reduce risk.

\subsection{Society and Economy}

Community development policies, plans, and programs for economic diversification and self-reliance are important in building the social capacity. Community goals need to be identified through a transparent and participatory process to guide development policies, plans, and programs. In this regard, there is Communal Development Plan (PLADECO) with a vision to economic development through the tourism development and improvement of fisheries sector with a limited implementation of this plan. Community needs skill development training program for the diversified livelihood which makes community more resilient because people may have the alternative livelihoods for the recovery after a disaster event like tsunami.

For the poor and marginal people of the society, there are social safety nets from where they can get help. However, sometimes these safety nets are not smooth and faster to help after a disaster. Only aid from different organizations and subsidy from government in few sectors like housing are available. However, the aid and subsidies in income generating sectors for starting a new business are insufficient. Social and cultural networks may be formal or informal mechanisms can be formed involving community people, cultural group, private sectors and nongovernmental organization to support a range of resilience-related activities. But in the local community here, unfortunately this kind of network is not so strong. For the faster recovery process special conflict resolution mechanism are essential. There is no social mechanism to solve the conflict in the community. Therefore, this is a network among community, municipality, regional government and NGOs can enhance the community resilience as safety nets for disaster-stricken communities through emergency medical supplies, shelter and food. Thus social safety nets, organized civic group, conflict resolution mechanism and community development plan enhanced community resilience, but need to be more effective for the better resilience.

\subsection{Resource Management}

Characteristics of a resilient coastal community are active management of coastal resources, sustain environmental services, diversified livelihoods and reduce risks from coastal hazards. In planning perspective, a resilient community should have policies and plans which are implemented and monitored for the effective management of natural resources. Here, land-use plan and communal development plan identified community resources partly. Land-use plan shows the zone of productivity, zone of touristic resource in a map. However, there is lack of clear demarcation of the natural resources and the plan for the management. There is no proper resource management plan to minimize the loss of resources and to maximize their protection for future uses and benefits. Resilient communities need to be aware of their relation with and dependence on coastal resources and to what extent the degradation of coastal resources puts them at risk.

Apart from the natural resource management, the financial and technical resource management are also important for a resilient community. After disaster, it is important for the community to get financial and technical help from the outside of the community. For that reason, regional and local level plans and networks are needed to be established from where people can get benefit. Regional government is channelizing financial and technical resource for community rebuilding process. In rebuilding and rehabilitation process, government is giving hundred percent subsidies. However, in the livelihood issue, like rebuilding fisheries, start business and tourism; local people get subsidies from the government which is insufficient. Therefore, people are depended on credit from bank, which is the only option for credit. This credit is accessible but with mortgage. Therefore, marginal group of the society who has no property, it is difficult for them to get credit.

\section{4: Land-use and Structural Design}

Resilient coastal community is characterized by the effective land use and structural design which are complement with environmental, economic, and community goals and reduce risks from hazards. Before the tsunami in Dichato, There was no detailed land use zoning except communal land use plan which is in a broader scale where land use category is mentioned only like residential zone, forest zone, productive zone etc. However, this zoning system never considers tsunami risk based on tsunami vulnerability assessment before this devastating tsunami.

After tsunami local and regional government understood the need to established land use policy and building standards to reduce the tsunami risk. Therefore, a tsunami vulnerability assessment has been done by the regional government as an input to master plan. Master plan of Dichato is published in 2010 which includes an effective land use zoning considering tsunami risk. This master plan divided whole Dichato in two zones primarily, which are tsunami risk zone and risk free zone. Tsunami risk zone are divided into three categories 
which are no habitable zone, anti tsunami housing zone and tsunami resistant housing zone. Policy limits the housing investment in no habitable zone but do not limit the commercial investment. Structural solutions include the protection wall in coast and a tsunami mitigation green belt (recreational park) along the coast. This plan also includes the house type with structural design of house for different zones. Two types of houses are introduced where anti tsunami house for relatively high-risk zone and tsunami resistant house for relatively lowrisk zone (See Fig: 2). these two types of house are in following figure.

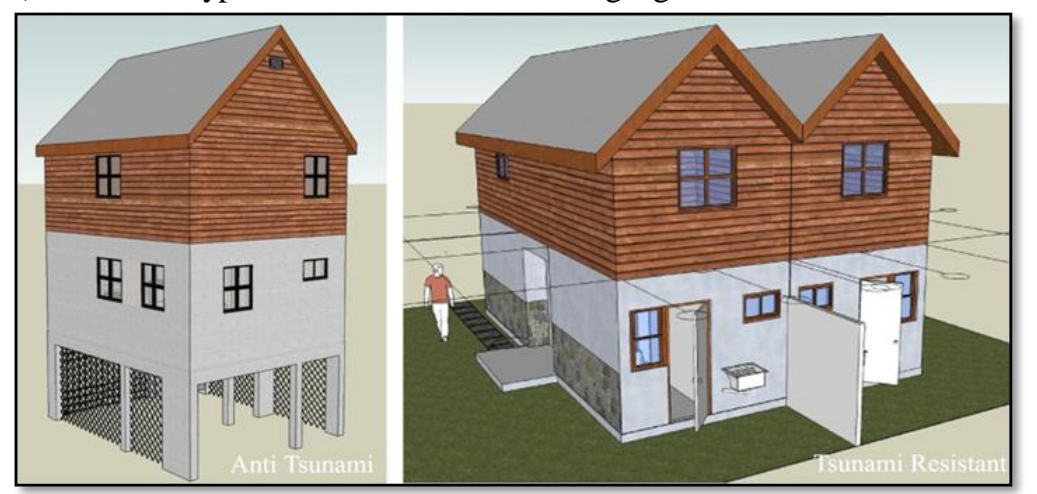

Figure 2: Housing Type of Tsunami Risk Zone in Dichato; Source: MINVU,

Building standard and codes are also adapted after tsunami, but it was very general for all coastal zones before the tsunami. That means, after tsunami area specific construction code and standard are adopted. Each sector has different standard of construction depending on the risks of flooding by tsunami, height of the tsunami wave and type of soil. For example, sector Miramar need to construct house above one-meter soil filling. To enhance community resilience it is also important to organize some outreach-training programs to improve compliance with land use policies and building standards. But in reality, these kinds of initiatives are limited in the community level.

\section{5: Risk Knowledge}

Risk knowledge is the awareness of tsunami hazard and risk. Community should consider this knowledge for the development decisions. A study on tsunami hazard risk has completed by a group of experts for Coliumo Bay and Talcahuano Bay after tsunami in 2010. This study considered the historical tsunami event, wave height of past tsunami, impact of these tsunamis, frequency of tsunamis and some other related issues. However, there is no plan for the routine assessment and updating the risk information regularly.

Community involvement in the risk assessment has the benefit in many folds. Firstly, risk assessment team can get and consider the knowledge of the local people that they have gained traditionally. Secondly, it helps to create community awareness on tsunami risk during the assessment period. Unfortunately, the community participation was limited in tsunami risk assessment. Another important issue is that the sharing of the risk information among the stakeholders. All agencies and organizations who are working on three domains (community development, resource management and disaster management) in different levels of government need to share this risk information. Risk information is needed to share among public institutions by staff meetings and presentations. However, community is an important stakeholder here, but the result of hazard and risk assessment study are almost secrete to the community. Risk information can be dissimilated in community through radio programs, brochures, meetings and participatory lectures. Formal education program exists to promote risk knowledge in school but not in community. In school, formal program namely "DEYSE" (De Evacuación y Seguridad Escolar) and "Francisca Cooper" teach about disaster risk but these programs are mainly focusing on earthquake issues.

\section{6: Warning and Evacuation}

Resilient community is capable of receiving notifications and alerts of coastal hazards, warning at-risk populations, and individuals acting on the alert. In civil protection plan, there are three basic types of warning level: Green Alert, Yellow Alert and Red Alert according to the severity of the disaster events. However, there is no tsunami specific warning system. Municipality has the responsibility to dissimilate the warning information after getting it from emergency office. Fire fighter and police use the sirens and hand mike to dissimilate. Apart from the community radio, media can also be played a vital role to spread this warning signal.

Human made warnning system is also important likewise mechanical alarm system. The local knowledge on natural phenomenon is orally transmitted through social networks formed in coastal towns through daily life activities. Knowledgeable neighbors raised the alarm and helped each other for a quick evacuation. Therefore, it is necessary to develop socio-cultural mechanisms enhanced by bottom-up risk 
management policies. It is important to promote the social knowledge on natural warning system generation to generation in community. The training exercises and moc drill is very much important to enhance resilience.

Resilient coastal communities should also have evacuation plans in place well in advance of receiving any hazard warning. After tsunami in 2010, ONEMI made an evacuation plan in cooperation with the local municipality. Municipal risk prevention and emergency office is implementing the evacuation plan in Dichato. Different types of signs are installed in different location in community. This evacuation plan for tsunami includes signs for tsunami hazard zone, evacuation direction and safety zone (See Fig: 3). This is a very new approach to enhance community resilient after tsunami. However, modification of this plan is also necessary to make it more convenient for the tourist.

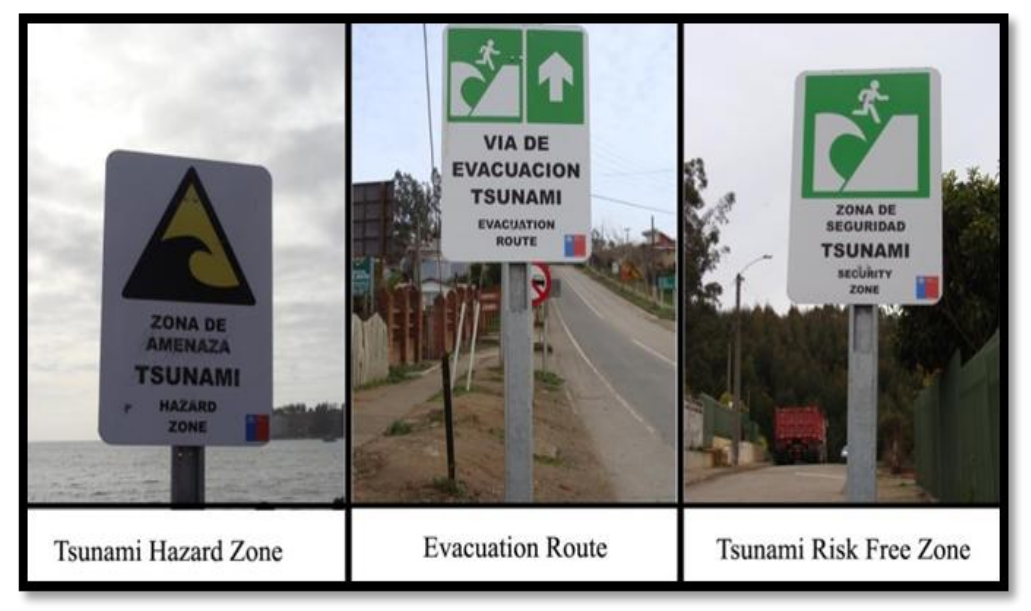

Figure 3: Signs for the Evacuation during Tsunami Event

This evacuation plan also did not include the individual special needs like children, woman and handicap. There is no special plan of the warning and evacuation for the people who need special consideration.

The warning does not consider the needs of the tourist because signal is in general and evacuation route sign are only in Spanish. Therefore, it is important to consider the needs of tourist in warning and evacuation plan. It is also necessary to make security guide available in all coastal touristic place.

\section{7: Emergency Response}

Emergency response is an important element for a resilient coastal community. Planning is required to establish mechanisms and networks to respond quickly to coastal disasters and address emergency needs at the community level. In municipal level, there is an emergency action plan for disaster. The plan aims to ensure the coordination of institutions involved in the emergency management and define institutional responsibilities before, during and after an adverse event occurred. However, this plan is very general to all kind of disaster. A tsunami specific emergency management plan is necessary to make the coastal community more resilient to tsunami. ONEMI coordinate and involved different organizations like military, police and fire fighter to rescue activities. NGOs also participate to provide health care, food and other support along with the government organizations. Dichato community also has local emergency office under the municipality. When tsunami came, Dichato emergency office communicates with police and fire fighters for rescue operation. However, emergency office itself has limited capacity to implement the emergency action plan. In addition, necessary action need to be taken to ensure that the emergency and lifeline supplies and resources are identified, stored in safe locations, and can be mobilized in a timely manner. But in the case of Dichato community there is no steps to store these emergency response materials.

\section{8: Disaster Recovery}

Resilient coastal community should have disaster recovery plan which are in place prior to hazard events that accelerate disaster recovery. There is no disaster recovery plan in regional, communal and local level to explain how recovery process can going on after the tsunami. Recovery plans should address short-term need like debris removal, temporary shelter, sanitation etc. Present plans and policies are considering the range of potential tsutnami impacts in this area. Recovery plan also need to consider tsunami hazard scenario, which can reduce the loss of tsunami and faster recovery process.

It is essential for the resilient community to pre-established coordination mechanisms at international, national, and local levels for disaster recovery. Here for the community, there is very limited pre-established 
mechanism for coordination. Regional government is coordinating with community leader through the mayor of the municipality for recovery process after tsunami. The secretariat of housing and urbanization (SERVIU) is playing a vital role for the coordination in housing recovery. The secretariat of technical cooperation (SERCOTEC) is working with fisherman and small scale businessman for the livelihood recovery after tsunami. But pre-establish mechanism of recovery with national government and international organization always helps for a faster recovery process. This information on recovery process is channelizing by the local desk of SERVIU, community leaders and by the direct meetings. Community people have group wise different meetings with organizations who are working on different recovery projects. All recovery process are very transparent to the local people however all process are slower than expectation. Due to the slowness of programs, community people sometimes think that they are getting wrong information.

The existing procedures, law and stakeholder in housing rebuilding case are supportive. People know how to apply for the grant and how to get it. The regulations and policy also opens the opportunity to get new house after the tsunami without paying. There are different types of recovery programs which are taking place in short-term and long term basis. Short-term housing program with basic service are taken and for the long term recovery in housing, there are solidarity fund for rebuilding the house with the people who has land before and also who do not have land. For the social recovery, an NGO, Hogar de Cristo is working with the municipality to recover the mental health, provide assistance in child education and working for the development of the woman. Some rebuilding programs also took place in fisheries and tourism sectors. These programs are enabling fishing and tourist activity in Dichato after tsunami.

\section{CONCLUSION}

Findings of this research are related to this community. However, some findings can be generalized for many coastal communities in Chile. Tsunami risk issue is not properly addressed and studied at local level. There is no routine assessment of tsunami risk. Therefore, local land-use plan, tsunami mitigation plan are not updated based on the tsunami risk. Proactive leadership in community is a good indicator for the governance, however community participation in plans and programs are not always effective. The community aims to create sustainable development through the use of natural resources but livelihoods are not diversified. Social networks and stakeholder networks are not strong. The community can get help and subsidy from the government but special needs of marginal section of the community are not well addressed. Coastal resource management is absent, only few issues regarding coastal resources are addressed in the land-use plan. Tsunami risks are carefully considered in the new master plan and structural design. However, all initiatives regarding land use and structural design are after tsunami. This new initiative will enhance community resilience to tsunamis.

There is very limited effort made to inform the community about disasters. There is no drill or training program for the community to educate about the risk. The community has some knowledge of the issues from campaign and experience. Planning the evacuation route is also a new aspect for this community after tsunami. Community engagement in the evacuation procedure is important. The community also needs to consider locating critical facilities outside of risk area. It is also needed to store rescue equipment outside tsunami risk area. A pre established disaster recovery plan is not exist in local level. Coordination mechanisms among institutions, donor agencies and different stakeholders are very important for faster recovery. This coordination mechanism is absent at the local level and needs to seriously considered. The following figure is the numerical expression of the findings of this research paper. This figures expressing the community resilience in eight dimensions on a scale poor (1) to excellent (5).

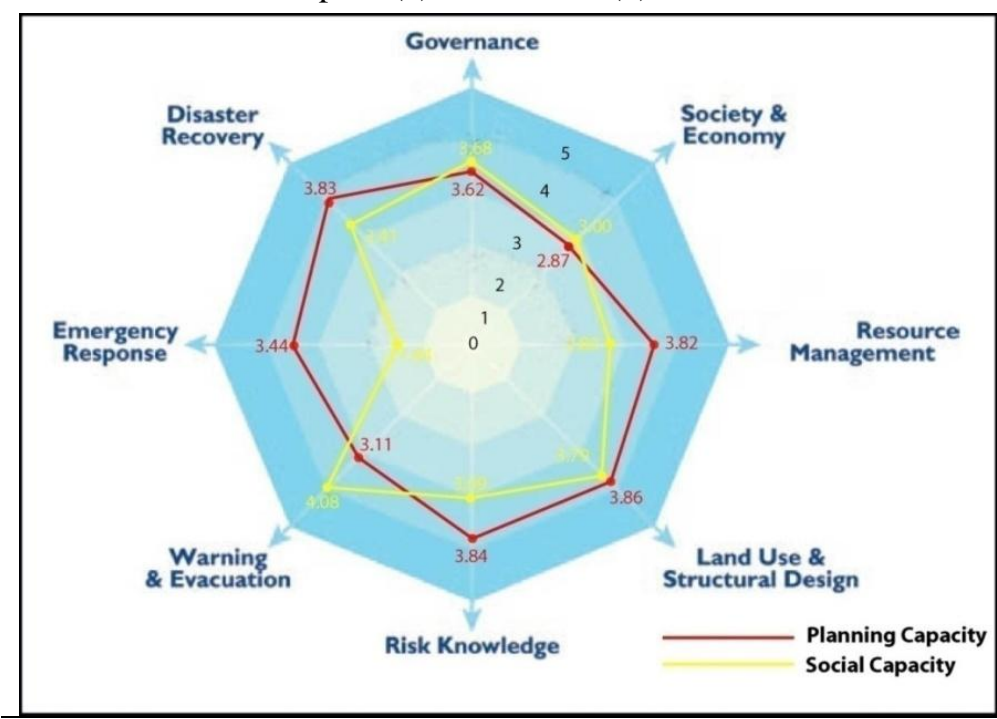

From the figure: 4 , it can be concluded that coastal community resilience to tsunami are medium in most dimension. In most cases, resilience elements have a score between three and four, where one represents poor and five represents excellent. Social capacity in warning and evacuation has a higher score, more than four. Social capacity in emergency response is poor due to the limited training and drill activity at the community level for emergency response. Even community engagement in emergency plan is very limited. Planning and social capacities have almost the same strength in 
governance, society and economy, and land-use and structural design dimensions. Social capacity is weaker than planning capacity in resource management, risk knowledge and disaster recovery. There are many scopes to enhance community resilience to tsunami in all dimensions of the resilience framework. Therefore, it is important to look at the weakness and initiate programs to strengthen social and planning capacities of the coastal community like Dichato.

This kind of research can bring many outcomes; firstly it can bring out the strength and weakness of the community. Secondly, Government and non government organizations can understand where there is gap for the policy and planning for tsunami preparedness. Thirdly, the local community can benefit from this research to gain an understanding of their problems.

\section{ACKNOWLEDGEMENT}

We would like to show our sincere gratitude to German Academic Exchange Service (DAAD) to provide fund for this research. We are very much pleased to thank to SPRING Chile, masters program in Faculty of Economic and Administrative Science, Universidad Austral de Chile where this research have been done.

\section{REFERENCES}

[1]. Madariaga, R., Me'tois, M., Vigny, C., and Campos, J. (2010). Central Chile finally breaks. Science 2010; $328: 181$.

[2]. Servicio Hidrogra fico y Oceanogra'fico de la Armada (SHOA). (2010). Informedela Investigación Efectuada al SHOA.

[3]. United States Agency for International Development (USAID). (2010). Chile - Earthquake: Fact Sheet \#11, Fiscal Year (FY) 2010

[4]. Bárcena, A., Prado, A., López, L., \& Samaniego, J (2010). The Chilean earthquake of 27 February 2010: An overview. United Nations publication. LC/R.2160.

[5]. Paton, D., Millar, M., \& Johnston, D. (2001). Community resilience to volcanic hazard consequences. Natural Hazards, 24, 157169.

[6]. Coles, E., \& Buckle, P. (2004). Developing community resilience as a foundation for effective disaster recovery. The Australian Journal of Emergency Management, 19, 6-15.

[7]. Kasperson, J. X. \& Kasperson, R. E. 2001. SEI Risk and Vulnerability Programme Report 2001-01. Stockholm Environment Institute, Stockholm.

[8]. Lichterman, P. (2009) Social capacity and the styles of group life: Some inconvenient wellsprings of democracy. American Behavioral Scientist, 52 (6), pp. 846-866.

[9]. Spellerberg, A. (2010). Building social capacity - not social capital. Blog at world press. http://wellsharp.wordpress.com/2010/07/08/building-social-capacity--not-social-capital/ (last accessed June 20)

[10]. Plan de Reconstrucción del Borde Costerro ( PRBC18), (2010). Gobierno Regional Bio-Bio.

[11]. United States Agency for International Development (USAID) (2007). How Resilient Is Your Coastal Community? A Guide for Evaluating Coastal Community Resilience to Tsunamis and Other Hazards. Bangkok, Thailand. 